Association for Information Systems AIS Electronic Library (AISeL)

Wirtschaftsinformatik Proceedings 2001

Wirtschaftsinformatik

September 2001

\title{
Integration and Flexibility: Expected and Undesired Effects in Information Technology Projects
}

Marco De Marco

Università Cattolica di Milano, marco.demarco@uninettunouniversity.net

Federico Rajola

Università Cattolica di Milano, frj@mi.unicatt.it

Roberto Ravagnani

Università Commerciale L. Bocconi, roberto.ravagnani@uni-bocconi.it

Follow this and additional works at: http://aisel.aisnet.org/wi2001

\section{Recommended Citation}

De Marco, Marco; Rajola, Federico; and Ravagnani, Roberto, "Integration and Flexibility: Expected and Undesired Effects in Information Technology Projects" (2001). Wirtschaftsinformatik Proceedings 2001. 41.

http://aisel.aisnet.org/wi2001/41 
In: Buhl, Hans Ulrich, u.a. (Hg.) 2001. Information Age Economy; 5. Internationale Tagung Wirtschaftsinformatik 2001. Heidelberg: Physica-Verlag

ISBN: 3-7908-1427-X

(C) Physica-Verlag Heidelberg 2001 


\title{
Integration and Flexibility: Expected and Undesired Effects in Information Technology Projects
}

\author{
Marco De Marco, Federico Rajola \\ Università Cattolica di Milano
}

Roberto Ravagnani

Università Commerciale L. Bocconi

\begin{abstract}
Summary: The by-now consolidated Business Process Reengineering approaches systematically emphasise the positive value of organisational integration along a logical sequence of interrelated activities (for example, the active cycle of the order or the development path of a new product). The advocates of these approaches maintain that a non-integrated business process tends to create redundancies, red tape and an inability to respond rapidly to unexpected changes or to new customer needs. By contrast, an integrated process should be marked by greater linearity, by non-redundant data, by increased flexibility and particularly by greater simplicity (see Davenport and Short, 1990). In the past five years, the astounding spread of integrated information systems (commonly known as ERP - Enterprise Resource Planning) has involved the wholehearted adoption of this philosophy and this further strengthened the managerial rhetoric of integration. In the light of such enthusiasm, the objective of this article could be encapsulated in the say: All that glitters is not gold. Metaphors aside, we shall endeavour to show how that, while process integration does indeed have positive effects, it also has unexpected and negative effects. In fact, paradoxically integration can herald greater information complexity, rigidity and ambiguity within responsibilities. So far as methodology is concerned data taken from the qualitative analysis of a company case study will be presented in depth. The company in question is a large industrial concern which was analysed six months after the introduction of an integrated information system aimed at replacing the previous systems in the administration-accounting areas and in those connected with the supply chain (purchase, sales forecasts, planning of production, distribution and order management). Naturally, the usual methodological principles are valid for analysing a single case: if a statistical generalisation is not possible, an analytical one, however valid, is licit, to the extent that the resulting data can facilitate a more thorough reasoning on theoretical concepts (Yin, 1989).
\end{abstract}




\section{Integrated information systems: general concepts}

Very briefly, (for more details we refer the reader to specialist publications in the field, such as Mertens, Bodendorf, König et al., 1999), the characteristics common to integrated information systems can be summarized as follows:

- They are based on a single shared database;

- They are organised in modules;

- They generally have an interface with other Business Information Systems;

- They are generally neutral vis-a-vis technological platforms;

- They can generally be configured, at least within a more or less wide range of pre-set options;

- They contain fully-fledged management philosophies crystallised in electronic form;

- They are based on client-server technologies.

Integration is, as the name suggests, their main feature; it represents the outcome of an evolution which has led to the progressive expansion of the automation logics of the logistic-production processes (MRP and MRP II) within administration and management frameworks. The main strength of an integrated system is its capacity to reduce information complexity by replacing fragmented, redundant and non-communicating systems with a single information platform. In theory, this operation offers two types of benefits: firstly, an increase in transparency, with availability of coherent data in all areas of the company'; secondly, greater fluidity in many processes, as a result of automation in the updating of every area's data (the workflow). For example, the activation of an order by a customer can automatically generate the updating of applications throughout the company administration, sales, warehouse and production.

\subsection{Empirical data}

As already mentioned, the case analysed concerns a large entity where an integrated system (namely SAP R/3, the leading product on the market) was implemented in most of its areas (excluded, but only partially so, were Human Resources Management - HRM, R\&D and a few residual support functions). Moreover the project had required that the processes involved in these areas be analysed and reengineered: in actual fact, therefore, the introduction of SAP represented a significant organisational change. The very introduction of an integrated system can contain ambigous implications in that different actors -according to the different positions they occupied along a particular process- experienced it as either a positive or negative thing. 
In general, the positive perceptions were linked to the behavioural change induced in interdepartmental relationships; the integrated system in the company in question helped to define better the mutual responsibilities between the commercial and production areas (especially in the respective sales forecasts and production planning units) and, thanks to the unique nature of the master data, to render impartial the basis upon which the two areas negotiated. In other words, debates no longer tended, as in the past, to be concerned with the veracity and the significance of the respective information, but rather to focus on the concrete balancing choices between commercial and production needs. On a more personal level too, the development of a common language, and more generally, greater rigour in carrying out processes improved the atmosphere within the company. This last effect is a direct consequence of the artificial interdependence emphasised by the new information systems, in that the onset of errors in a particular phase, besides triggering anticipatory problem-solving initiatives in operations down the line, gave rise to an analysis and correction process which could not but involve the operators of the phases at source. Actors belonging to different, and until that moment non-communicating, areas were obliged to start talking to, and co-ordinating with one another, the penalty being the blockage of the entire process.

In this sense, quite apart from the fact that it ensures greater reliability of data and clarity of responsibilities, the integrated system has been interpreted by many as an "educational" tool and one conducive to professional growth, in so far as it has created the conditions for greater understanding at all corporate levels. In general, many interviewees in this case study expressed their conviction that SAP, by virtue of its integration potential, can have positive effects, particularly in the long term, both on a "non-tangible" and cultural basis and as a platform for further value-adding automation or a melorative interventions on processes, organisation and user competencies.

However, alongside these positive aspects integration has also created unexpected negative effects. Surprisingly, given the possibility of tracing the data path, many users came up against a greater difficulty in identifying the bottlenecks along a given process. In the sales administration area, for example, the system created such intricate interdependencies among the different activities that at times it became difficult to isolate the cause of a blockage in the order cycle and to intervene "surgically", so to speak. Previously, the greater isolation among the systems enabled single problems to be solved quickly (even if naturally, they were then required additional manual adjustments in all interdependent systems) and this, for those activities where time was an important factor such as customer relations, certainly represented an advantageous point. Besides this, the intrinsic breadth of the system has made it at times difficult for the user (especially if non expert) "to surf" within it without getting lost or using more time than before ton retrieve information.

Another negative aspect of integration derives from the difficulty involved in introducing changes in the processes, in so far as every change required that the ef- 
fects on other areas be taken into consideration, thus inevitably prolonging the intervention times of IT specialists and increasing the need of co-ordination with other areas.

It is interesting to note how many interviewees perceived their activity as being the "end" of a process, and therefore subject, more than others, to paying the consequences of inefficiencies made along the phases nearer the "source" of the process; in other words, the majority of users, irrespective of the area to which they belonged, felt at a disadvantage in that they saw themselves as collectors (as "lightning rods") of the errors made by other users in other areas. In the purchase/procurement process, for example, payable accounting had become a mere body for paying out, while data inputting and invoice checking were delegated directly to the end user (in this case line functions), which often made mistakes or used the process in an opportunistic manner. The senior management, for example, tended not to make a final balance of the costs if the latter were not in compliance with budget limits: this was an opportunistic attitude which falsified the fluidity of the process and weighed heavily on relations with suppliers. The latter, in compliance with their habits, often called the payable accounting department (and not the end users) to ask for their invoices, a problem which could not be solved by operators in this area.

In general, errors were considered more dangerous than in the past, as integration reverberated on many more units. Furthermore, whenever errors were made by external actors (whether customers or suppliers), the process of intervening became even more problematic.

Another interesting perception, partially in contradiction with the above, derived from the affirmation that greater informative integration meant less interpersonal interaction between representatives of the different areas. Such a perception becomes clearer especially in the the commercial and industrial areas all along the sales forecast/production planning process. In other words, most of the information was transmitted through the IT medium or a few interface roles. So that meetings and verbal communication between the two areas had diminished radically. This has involved the risk of reducing the degree of socialisation and the informal resolution of conflicts. It seems that this phenomenon particularly affected those actors who, before the introduction of SAP, were often used to interdepartmental relationships. The system did not therefore act as that "cultural link" for people used to have interdepartmental relationships. On the contrary it seems to happen for people who were less used to interact with colleagues from other departments. 


\section{Implications}

\subsection{Implications from research methodology}

These data should lead us to the consideration that, in synthesis, integration is not merely either an objective or technical fact, but depends on the established habits and the position of each actor throughout a process, on his/her knowledge of the system and of the process itself and on his/her more or less opportunistic behaviour. In the same way, integration is not necessarily a symptom of greater flexibility and better process performance, but can create negative secondary effects capable of counteracting the direct benefits.

The first reflection which springs to mind in view of these results regards methodology and begs the question as to the usefulness of an interpretative approach to research. By this is to be understood technology considered as a socially constructed phenomenon, the systems design and use of which depend not only on technical criteria, but on certain factors such as organisational culture, user competence, power games and even chance. Interpretative approaches tend to favour qualitative research methodologies and are particularly suitable for analysing ambiguous, dynamic phenomena such as processes of organisational change (Myers, 1997).

The main advantage of this approach resides in its capacity to verify the "real" effects of the introduction of new technologies on user behaviour, including the discovery, as in this case, of unexpected and paradoxical secondary consequences. Apart from the obviousness inherent in the statement that the opinion of those directly involved almost always remains the source of more interesting and truer data, the limited diffusion of analyses of this kind (apart from the researches mentioned) is to be ascribed to the practical difficulties involved in conducting them to the difficulty of generalising them in statistical terms, as well as to an unhappy prejudice (typically Anglo-Saxon) that qualitative methods involve a low level of scientific rigor.(see in is regard, Mingers and Stowell, 1997, or Checkland and Holwell, 1998).

Obviously, quantitative process measures (for example performances measured in terms of costs, time and quality before and after the introduction of the system) continue to be useful, complementary and non-replaceable with respect to qualitative analyses yet they can at most "indicate" possible causes of malfunctioning; on their own they are probably incapable of "understanding" its source and combined effects. Even from a diagnostic point of view, therefore, an interpretative approach may very well offer clear advantages. In addition, often the consequences (positive or negative) of an information system on process performance may be measured only after a certain lapse of time and in any case with considerable caution as regards methods (Beretta, 1998), while interpretative analyses may 
be carried out over the entire life span of an implementation project and therefore supply significant and timely elements re possible pathologies and corrective interventions.

Furthermore, the very dynamism inherent in the adjustment process between organisation, users and technology rules out static observations. The evolutionary nature of the process demands that it be monitored throughout the various phases of the project.

\subsection{Implications on organisational design}

A second series of considerations relates to the validity of the models of rational system development of organisations sponsored by the advocates of BPR. It is clear that the application of an integrated platform to an organisation still structured in functional departments (as in the case analysed) may produce paradoxical effects. In theory, more integrated processes should reduce organizational complexity and redundancy but what they actually do is create further artificial interdependence among functions. The short-term result is that those interdependencies - in order that they be managed - demand further tools and co-ordination mechanisms, and this merely increases organisational complexity and transaction costs.

For example, if interdependence between various functions becomes frequent, complex and uncertain, it could be worthwhile investing in integration organisms or linking points. We have emphasised that a short term result is in question, as it is possible (and to be hoped) that over time such interdependencies lead to an adjustment process in which even the organisational responsibilities adjust to the changes in the information flows and adopt an organisation which is genuinely geared towards processes, even if only informally. It is, however, ironic that the immediate effect of these systems may look similar to what was supposed to be eliminated. On the other hand, this should not come too much as a surprise: the consolidated models of organisational design (for example, Galbraith, 1973) have for a long time shown that an increase in the degree of interdependence among activities is in itself a factor which increases rather than decreases the complexity and thereby, also the cost of the organisation.

As the organisations which adopt a true process-based structure are still extremely rare, it might be worthwhile reflecting more critically than has been done to date on the compatibility between information integration and functional organisation. The issue will almost certainly become even more crucial as a result of the extension of systems integration beyond the boundaries of companies (i.e. suppliers and customers), a development which marks the impetuous wave of e-business projects. In this case too the principle of integrated systems remains, yet the increase in interdependence with regard to actors outside the direct control of companies (such as customers, distributors and suppliers) may pose questions of co-ordination even greater that those experienced up until now. 


\subsection{Results of the implementation activities and research questions}

The results of the empirical analysis bring to the fore evident another aspect: the flexibility (or reduction of staff and workload) induced by integration is a mostly subjective fact. It appears to depend on factors such as:

- Personal knowledge of process and system functioning. The greater the ability of an individual user 'to surf' within the system, the greater is his/her capacity to identify and resolve problems. In other words, users expert in the information system tend to perceive a greater degree flexibility than do occasional users.

- Position assumed along the process. The more one's activity depends on the input supplied by other actors, the greater the risk of feeling bound by their choices and particularly by their errors. The curious aspect which emerged from the analysis is that the increase in integration actually tends to awake in actors the impression of being "on the receiving end" with regard to the rest of the organisation. In other words, everyone feels a great danger of having to pay for other people's decisions: therefore the degree of flexibility is generally perceived to be less.

- The degree of opportunism allowed or induced by the information system: if the structure of the reward (broadly speaking) system does not encourage the individual users to assume responsibility for what they do nor punish all behaviour harmful for end users, those "at source" will not perceive any substantial changes in their activities.

- Coherence between the duties of individual actors and the process induced by the information system: the greater the distance between the often limited amount of information necessary for carrying out one's activity and the mass of information available at the front-end, the greater the sense of confusion within the system.

All these factors together confirm the importance of learning and adjustment processes in determining the effects of an organisational change. In other words, measuring in an "objective" manner the degree of information and organisational integration offered by an information system is irrelevant because in actual fact it depends on the subjective perception of the individual users, on their ability to use the system, on their understanding of what is happening in other areas, on the advantages and disadvantages stemming from the change in process and on the degree of freedom conceded when carrying out activities.

This set of phenomena may be traced back to the so-called technology "structuring" processes (Orlikwoski, 1992): the process of introducing an information system is a three-fold one (1) whereby technology is progressively charged with significance by (2) the organisation and (3) the individual actors. It in turn transforms 
the organisation and informs, binds and supports the activities of the actors in an iteration process of mutual adjustment.

From the pragmatic viewpoint of project management, the emphasis put on structuring dynamics as opposed to the static system design within an organisation also implies a shift in attention from the configuration activities of an information system to activities oriented towards managing the process of learning and organisational change (Ravagnani, 2000). In simpler terms, a perfectly embedded system is useless if there are no users able to operate within it.

Shifting attention to organisational learning means asking questions such as:

- What type of user involvement should be adopted in the course of the system design activities and during the introduction of the information system?

- How might one speed up the learning process of users during the implementation phase, so as to identify and reduce the dysfunctions, which typically arise during the first months in which the information system is deployed?

- Is it possible to foresee different learning paths vis-a-vis different types of user?

- In what measure and when is it necessary to intervene on organisational variables such as the responsibility structure and the reward systems? In other words, does it make sense to first integrate the processes and then adjust the organisational structure?

- How does one keep organisational attention high not only during the implementation phase, as often happens, but also while the system is being used, when the system crystallises and the project group vanishes?

- Which "organisational interfaces" (Trauth and Cole, 1992) should be envisaged for managing the learning process of users during the utilisation phase?

- How can attention and a sense of responsibility be ensured with regard to activities further down the line than one's own?

- Given that the degree of perceived flexibility and importance of a system appears to be a function of the degree of its utilisation, how can occasional users be induced to become systematic users?

Many of these questions are not systematically taken into consideration in the main methodologies of information system implementation and, this being the case, call for explicit planning and management activity rarely to be found in practice. Alternative methodologies proposed by organisational theorists (Checkland and Holwell, 1998; Avison and Fitzgerald, 1997; Ravagnani, 2000) are beginning, with difficulty, to introduce some of the above considerations within the most common information systems development approaches, so as to integrate technical system development methodologies with attention to organisational learning dynamics. 


\section{Conclusions}

The rigidity of integrated information systems as identified and analysed in this article is not commonly associated with them. In fact, it is far more common for them to be impugned for being bearers of a deterministic and inflexible management logic to which the company adopting them must inexorably submit. Alternatively, these systems are often considered as rigid in time, in the sense that, once implemented, it is difficult to make radical changes without incurring great "reequipping" costs. In stark contrast rigidity is seen in this contribution not as intrinsic to the systems, but as induced in the processes managed by them: it is the direct consequence of their main characteristic, integration, which, although bearer of positive changes, can herald unexpected and paradoxical consequences. For example, more integrated processes can be less efficient, more complex and redundant compared to non-aggregated processes. In other words, an organisation oriented more towards processes can be more rigid and inefficient than the abhorred traditional organisation full of "functional silos".

Integration can at one and the same time be the cause both of flexibility and rigidity. Whatever the end effect, it should be clear that it is an organisational factor (not merely technological) and subjective, and must therefore be treated as such. Its organisational and subjective nature has important implications for research methodologies, for organisational design models and on for management approaches to information system implementation projects. In particular, it has been shown how the degree of perceived rigidity is a function of the effectiveness of the organisational and individual learning process and can be usefully interpreted as the result of a dynamic structuring game between technology, actors and organisation.

Some interesting development can come from CRM initiatives. Several companies are now planning to integrate ERP with sales force, customer service and support and technology-enabled marketing systems. CRM is among the most important contemporary business process applications. It consists of three major process areas: sales force automation, customer service and support and technology-enabled marketing. In simple terms, CRM enables the collection of customer data from multiple interface points and the access, analysis and distribution of that data across the enterprise. Recent researches have shown that a growing number of enterprises now embrace CRM as a critical business process requiring support from all parts of the business. This dynamic is driving a definitive trend toward CRM and ERP integration. The tantalizing promise dangled by ERP suppliers seeking growth in the CRM game is the potential to offer enterprise solutions spanning internal and external processes that can be delivered and supported through a single, familiar and dependable entity. This integration is not without challenges, however. In reality, merging CRM functions focused on increasing revenue with ERP functions typically focused on reducing costs creates architectural as well as cultural challenges. In reality, merging front- and back-office 
strategies is not easy, either culturally or architecturally. Culturally, there remains a huge discrepancy in these goals. CRM, especially in the areas of sales force automation and field service, may involve highly remote customers. Back-office functions mainly remain at the office. The customer-oriented users of CRM typically require relatively high degrees of unstructured content in their information - e-mails, notes and documents. In comparison, ERP is more transactionally oriented. Several processes need to be reengineered or redesigned. Some of them will have strong impacts on working methods.

Lastly, it may be worthwhile highlighting how an integrated information system may be flexible in its entirety only at the expense of the flexibility of its individual users. This concept of sacrificing individual activity for the good of the entire system is one of the recurring leit motifs of process organisations (see for example the contrast between functional efficiency and process efficiency) and is to be found in general in many debates on the nature itself of the concept of flexibility within an organisational and economic framework. The result which emerges repeatedly is that the increase of flexibility within one framework seems to call for an ever-increasing rigidity in another, correlated framework.

\section{References}

AVISON, D.E. E FITZGERALD, G. 1997, Information Systems Development: Methodologies, Techniques and Tools, Maidenhead, McGraw Hill.

BERETTA, S. 1988, La misurazione dell'impatto dei sistemi ERP sulla gestione: problemi di metodo e linee guida di intervento. In Amigoni, F. e Beretta, S. (ed) Information Technology e creazione di valore: analisi del fenomeno SAP, Milano, Egea.

CHECKLAND, P. E HOLWELL, S. 1998, Information, Systems and Information Systems, Chichester, Wiley.

DAVENPORT, T.H. E SHORT, J.E. 1990, The new industrial engineering: Information Technology and Business Process Redesign, Sloan Management Review, Summer, pp. 11-27.

GALBRAITH, J.R. 1973, Designing complex organizations, Reading, Addison Wesley.

MERTENS, P., BODENDORF, F., KÖNIG, W., PICOT, A., SCHUMANN, M. 1999, Informatica aziendale, Milano, McGraw-Hill.

MINGERS, J. E STOWELL (ed) 1997, Information Systems: an emerging discipline?, Maidenhead, McGraw-Hill.

ORLIKOWSKI, W.J. 1992, The duality of technology: rethinking the concept of technology in organizations, Organization Science, Vol.3, n.3, august, pp.398-427.

RAVAGNANI, R. 2000, Information technology e gestione del cambiamento organizzativo, Milano, Egea. 
TRAUTH, E. E COLE, E. 1992, The organizational interface: a method for supporting end users of packaged software, MIS Quarterly, march, pp.35-53.

YIN, R.K. 1989, Case study research, London, Sage. 